\title{
Dobras atectônicas em Crostas Ferruginosas de Pirapora do Bom J esus-SP e Bacia Terciária de São Paulo
}

\author{
J oel Barbujiani Sígolo ${ }^{1} \&$ Marcelo Altafini² \\ ${ }^{1}$ Departamento de G eologia Sedimentar e Ambiental - Instituto de G eociências - USP \\ Rua do Lago 562, CEP 05508-900, São Paulo, SP \\ 2Programa de Pós-Graduação em G eoquímica e Geotectônica - Instituto de Geociências - USP
}

Palavras-Chave: Origem, crostas ferruginosas, dobras atectônicas, dados geoquímicos e estruturais.

\section{RESUMO}

São discutidas neste trabalho as hipóteses de gênese tectônica e geoquímica de dobras em crostas ferruginosas na Bacia Terciária de São Paulo situadas na Vila Madalena e em sedimentos correlatos na região de Pirapora do Bom Jesus. $\mathrm{Na}$ análise deste problema empregou-se microscopia óptica, micromorfologia de minerais, texturas e estruturas secundárias, análises químicas totais e pontuais em MEV/EDS e análise de minerais pesados. Foram utilizados diagramas de Schimdt-Lambert para análise de parâmetros geométricos, morfológicos e orientações preferenciais das dobras e fraturas, tanto nas crostas como em padrões regionais de rochas encaixantes.

As crostas ferruginosas apresentam organização textural, composição química e mineral semelhantes (basicamente hidróxidos de ferro - domínio da goethita - argilas caoliníticas e quartzo), embora encontrem-se encaixadas em litologias diferentes e contextos geológicos distintos. Os diferentes dados obtidos indicam origem das crostas a partir da cimentação por hidróxidos de ferro oriundos do sedimento encaixante. A diferença reside apenas no empobrecimento $\mathrm{em}^{\mathrm{Fe}} \mathrm{O}_{3} \mathrm{O}_{3} \mathrm{e}$ enriquecimento em $\mathrm{SiO}_{2}, \mathrm{Al}_{2} \mathrm{O}_{3}$ e elementos alcalinos no sedimento, inverso do observado nas crostas ferruginosas.

Comprova-se esta origem por diferentes diagramas geoquímicos discriminativos, exibindo evolução a partir do sedimento encaixante em direção as crostas ferruginosas. Tal evolução deve-se a remobilização e concentração de hidróxidos de ferro, devido a deslocamento descendente do nível hidrostático, acompanhado de ascenção do relevo.

Não existem similaridades entre a geometria das dobras nas crostas ferruginosas da região de Pirapora e os padrões de dobras regionais. No entanto, as fraturas observadas devem ter sido originadas por reativação tectônica de sistemas de falhas regionais (Taxaquara, Jundiuvira e Romeiros). Estas fraturas condicionaram o fluxo d'água, permitindo que hidróxidos de ferro precipitassem no interior das mesmas.

Keywords: origin, iron crust, atectonic folds, geochemistry and structural data.

\section{ABSTRACT}

This paper discusses the genesis of folds in iron crust developed in Tertiary sediments of the São Paulo Basin (São Paulo-SP) and sediments in Proterozoic metasediments host rocks of the São Roque Group in Southeastern Brazil.

Both iron crusts made up basically of iron hydroxides and present textural organization, similar chemical and mineralogical composition, although they are located in different rocks and geologic settings. They are constituted basically by iron hydroxides.

Diverse diagram link the evolution of both sedimentary host-rocks and iron crusts composition, to a geochemical origin. These iron crusts were formed by remobilisation and concentration of iron oxides and hydroxides, originated by the descending meteoric water and groundwater level oscillation, related to seasonal climatic variations and uplift relief ascending movements.

No correlation was observed between structural data for iron crust fold and tectonic fold or regional deformation patterns in host-rocks. This indicates that tectonic processes of folding where not directly involved in the origin of this folded iron crust.

In addition, fractures in the Pirapora outcrop formed by neotectonic reactivation of regional lineaments, were the conduits for water flow, allowing iron oxides and hydroxides are to be precipitated. Oxides and hydroxides are precipitated obliquely to the fractures in the dransdown cone formed by the groundwater level down. The group formed by the deposition of this oxides and hydroxides in the dransdown cone show structures like folds delineates the pattern and feature of folded iron crusts observed in this outcrop. 


\section{INTRODUÇÃO}

A existência de crostas ferruginosas envolve reorganização de relevo quase sempre promovido por movimentos ascensionais de porção importante da topografia que as contem (Ambrosi \& Nahon, 1986; Beauvais \& Colin, 1993), gerando modelado geomorfológico específico quando de sua existência (Goudie, 1973). As crostas ferruginosas dobradas descritas neste trabalho reportamse a duas áreas distintas: uma situada na Bacia Terciária de São Paulo, na Rua Girassol, bairro de Vila Madalena (São Paulo, SP) e outra em Pirapora do Bom Jesus.

A origem destas “dobras” foi por muitos anos explicada sob diferentes hipóteses. Por um lado, uma interpretação sugerindo origem tectônica (proveniente de deformações modernas Quaternárias/Terciárias). Por outro, uma origem geoquímica, associada a remobilização e concentração de hidróxidos de ferro. A primeira referência sobre estas crostas ferruginosas na Bacia de São Paulo foi efetuada por Suguio \& Barbour (1969). Posteriormente, Sígolo \& Ohnuma (1996) apresentam proposta para sua origem e evolução. Ambos trabalhos, no entanto, não trazem esclarecimento quanto à existência dos dobramentos a elas associados.

$\mathrm{Na}$ tentativa de esclarecer a origem destas estruturas, foram aplicados estudos comparativos da constituição química e geoquímica das crostas e das rochas encaixantes e matriz destas crostas, bem como de diferentes materiais encontrados nas fraturas dos afloramentos.

\section{MÉTODOS}

A amostragem dos materiais foi executada em perfis, sendo três no afloramento da rua Girassol e cinco em Pirapora do Bom Jesus. Nas amostras das "dobras" (cros- tas), do sedimento encaixante e da matriz (amostras indeformadas e totais), foram realizadas análises micromorfológicas, análises químicas totais, análises químicas pontuais qualitativas e semi-quantitativas em MEV/ EDS e análises mineralógicas (DRX e separação de minerais pesados).

Os dados provenientes das análises químicas totais foram tratados em diagramas geoquímicos visando comparar o conteúdo químico dos elementos maiores nos perfis e obter relações de similaridade ou não entre os materiais investigados. Além disso, foram realizadas análises geométricas das dobras nas crostas ferruginosas (direção preferencial de flancos, charneiras, planos axiais das dobras nas crostas ferruginosas), sendo posteriormente comparados com as mesmas feições estruturais disponíveis na literatura sobre as rochas encaixantes (dobras e fraturas).

\section{AFLORAMENTO DA RUA GIRASSOL - VILA MADALENA - SÃO PAULO, SP}

O afloramento possui $40 \mathrm{~m}$ de extensão e $5 \mathrm{~m}$ de altura. Exibe sequiência rítmica de crostas ferruginosas "dobradas" constituídas por hidróxidos de ferro (goethita) de cor marrom escura (Figura 1 e 2).

O sedimento encaixante constitui-se de material arenoargiloso de cor marrom-amarelada, contendo grãos de quartzo de 0,2 a $1,5 \mathrm{~cm}$ e feldspatos alterados. Ocorrem também intercalações de níveis quartzosos pouco espessos $(0,5 \mathrm{~cm})$. Este afloramento e outros associados à Bacia Terciária de São Paulo foram descritos por Sígolo \& Ohnuma (1996), quando foi proposta a evolução e origem das diferentes crostas ferruginosas existentes nesta bacia sedimentar.

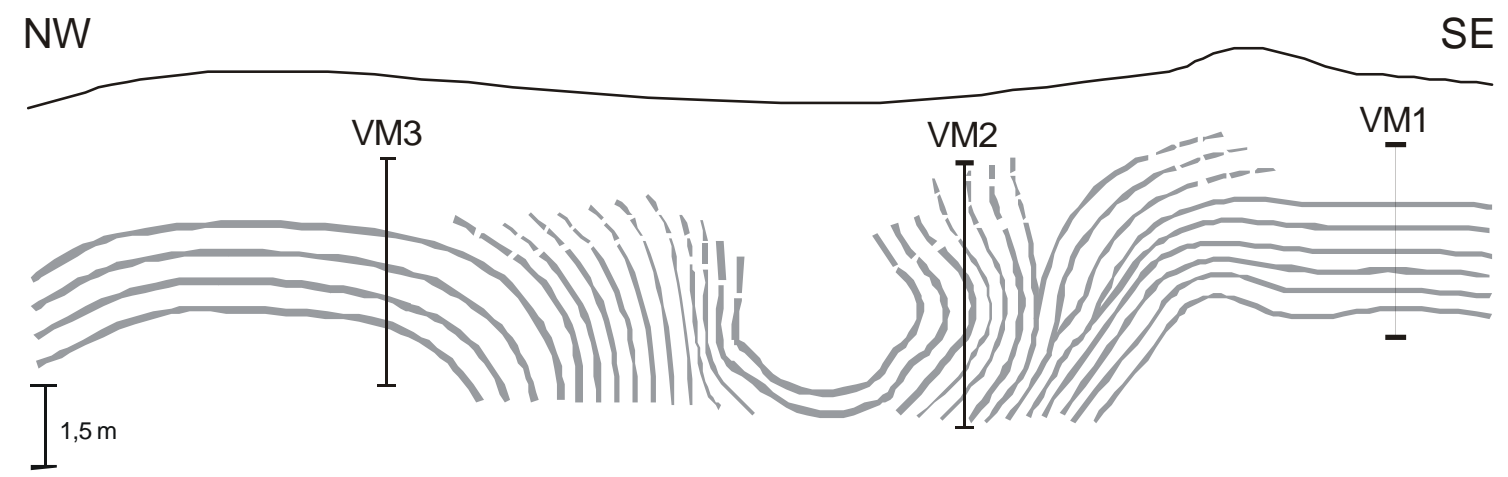

Figura 1: Croqui esquemático do afloramento da Vila Madalena, exibindo a localização dos perfis de amostragem (VM). 


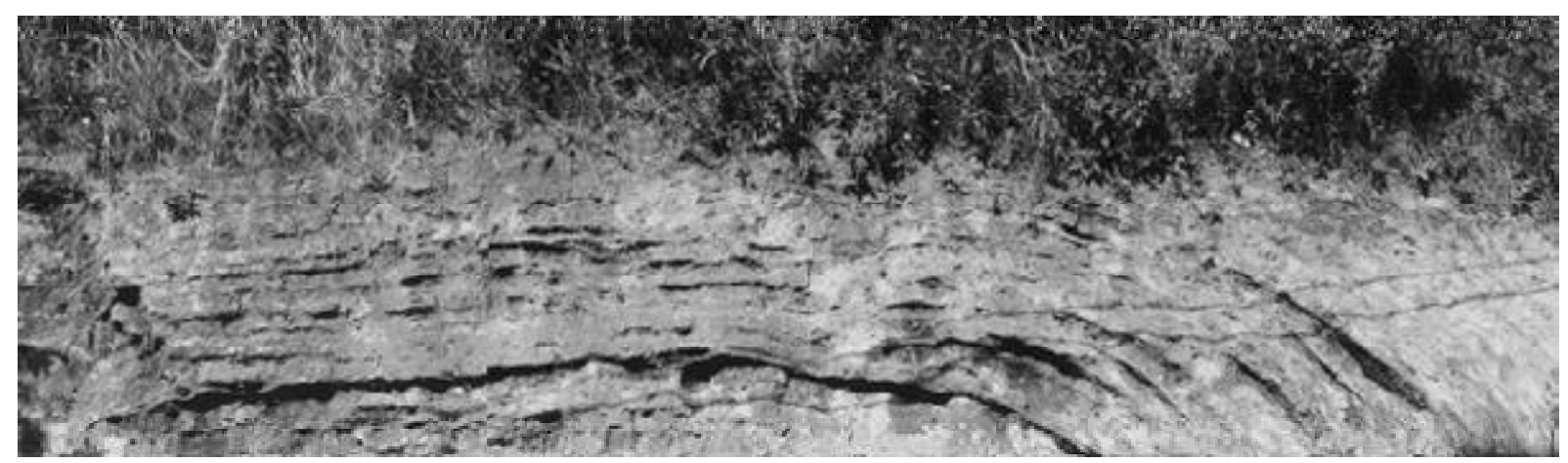

Figura 2: Fotografia correspondente a porção esquerda do afloramento esquematizado na Figura 1.

\section{AFLORAMENTO DE PIRAPORA DO BOM JESUS, SP - KM 53 DA ESTRADA DOS ROMEIROS}

Neste local, as crostas ferruginosas "dobradas" constituem-se predominantemente por goethita. São encaixadas em sedimento argiloso avermelhado, com clastos de quartzo leitoso e filitos do Grupo São Roque (Formação Pirapora do Bom Jesus).

Exibe $140 \mathrm{~m}$ de extensão e $20 \mathrm{~m}$ de altura e dividese em porção com (120m de extensão) e porção sem dobras (20m de extensão) (Figura 3 ). A espessura das crostas dobradas varia de 1 a 10 centímetros e são visíveis a partir da base do perfil. Alcançam até $15 \mathrm{~m}$ de altura e são capeadas por couraça ferruginosa indeformada com $20 \mathrm{~cm}$ de espessura por toda a extensão do afloramento.

Quatro grupos de fraturas e falhas foram diagnosticados (G1, G2, G3 e G4) (Figuras 3, 4 e 5). O grupo $\mathrm{G} 1$, constitui-se de fraturas individualizadas, sem preenchimento e o grupo G2, de fraturas preenchidas por hidróxidos de ferro, com até $10 \mathrm{~cm}$ de espessura. Estes dois grupos limitam as dobras (F2, F3, F4, F5, F8 e F9 - Figura 4). O grupo G3 representa um conjunto de fraturas pouco espessas $(2$ a $5 \mathrm{~cm}$ ), preenchidas por hidróxidos de ferro. Estas fraturas ora condicionam o fechamento das "dobras", ora cortam as mesmas (CF Figura 4 e 5). O grupo G4 constitui-se de falhas que cortam e deslocam as crostas deformadas (F7, F10 e F11 - Figura 4 e 5).

\section{RESULTADOS}

\section{Afloramento da Rua Girassol, Vila Madalena}

\section{Caracterização dos diferentes materiais}

As determinações em DRX e a análise de minerais pesados de amostras das crostas ferruginosas e da matriz confirmaram a existência de quartzo, biotita, argilo-mineral do grupo da caolinita, hematita, goethita e ilmenita.

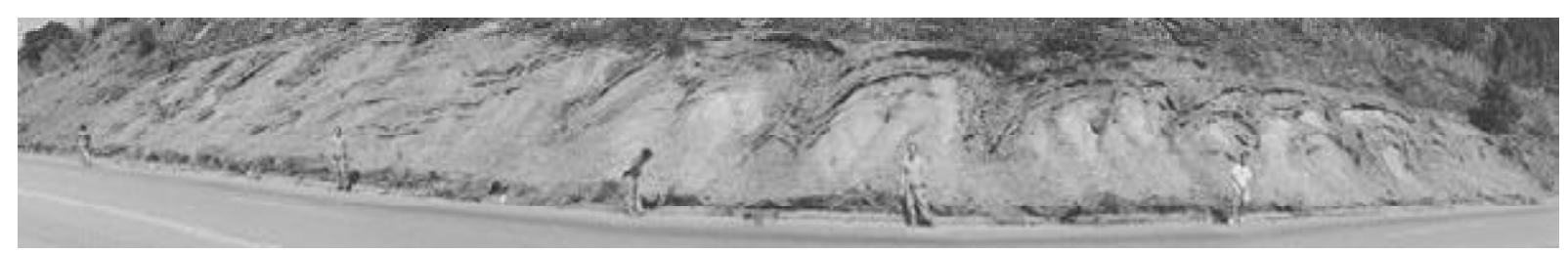

Figura 3: Montagem fotográfica do afloramento da Estrada dos Romeiros, Km 53, Pirapora do Bom Jesus-SP. 


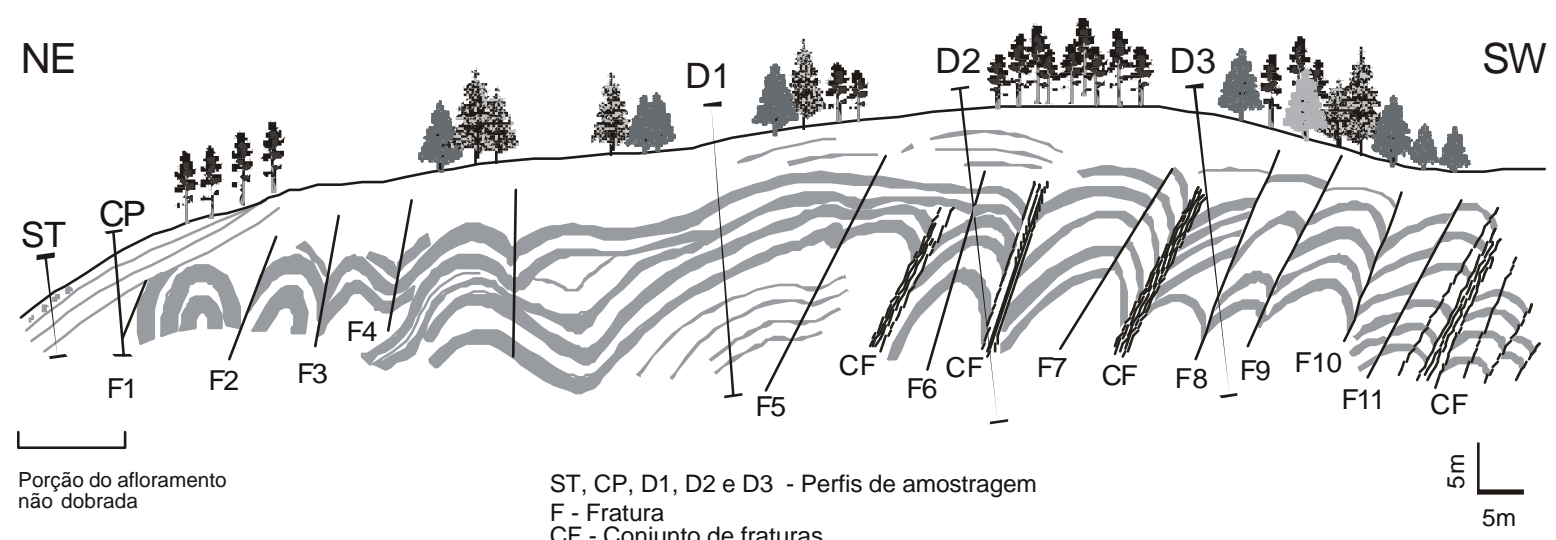

Figura 4: Croqui esquemático do afloramento de Pirapora, exibindo a localização dos perfis de amostragem e os sistemas de fraturas e falhas.

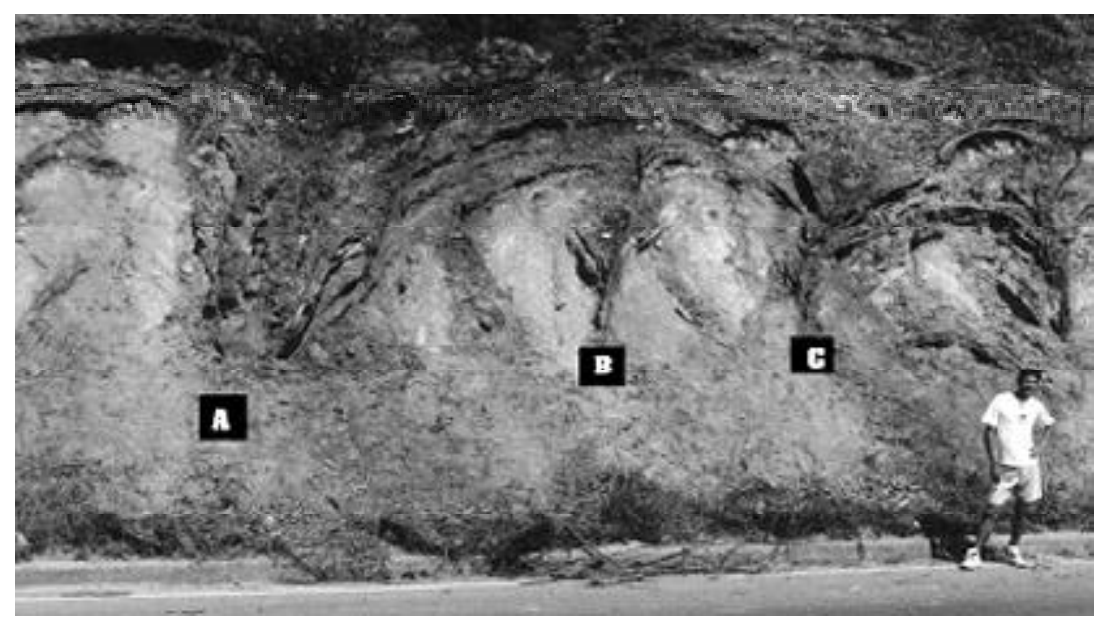

Figura 5 : Fotografia de parte do afloramento de Pirapora exibindo três conjuntos de fraturas: (A) - G rupo de fraturas do tipo $G 3$, preenchidas por hidróxidos de ferro. (B) - Fraturas individualizadas, preenchidas por hidróxidos de ferro, ora truncando os flancos das "dobras" (G4), ora encaixam as mesmas (G2) (C).

Anatásio, estaurolita e zircão são acessórios.

Na microscopia óptica foi possível identificar-se alguns minerais primários representados predominantemente por quartzo e, secundariamente, por turmalina e mica (biotita). Os grãos de quartzo apresentam-se angulosos a subangulosos. Alguns grãos apresentam feições de corrosão ou microfissurados. As fissuras intraminerais encontramse preenchidas por hidróxido de ferro (goethita) (Figura 6). Estas feições são indicativas da invasão do plasma goethítico sobre plasma caolinítico (matriz). Além disso, apresentam remobilização de hidróxidos de ferro na re- gião de contato entre o plasma caolinítico da matriz (direita da Figura 6) e o plasma goethítico da crosta (esquerda da Figura 6).

No setor das crostas, os grãos minerais encontram-se envoltos por plasma ferruginoso, fino e compacto, de cor marrom avermelhada. No setor da matriz, o plasma possui cor marrom amarelada (Figura 7 e 8). São observadas fissuras e vazios, preenchidos por argila e hidróxidos de ferro, algumas delas exibindo bandamento concêntrico formado pela segregação de ferro e argila (ferriargilans zonados) Figura 8. 


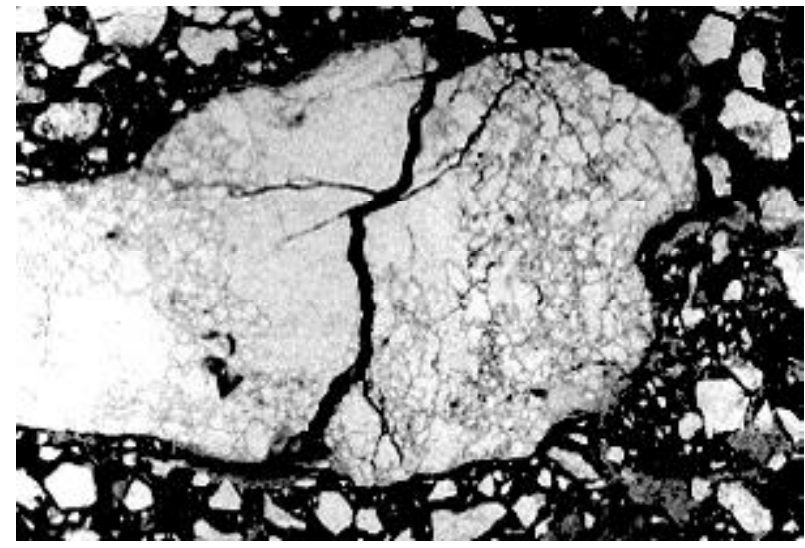

Figura 6: Fotomicrografia em luz natural, exibindo fissura preenchida por hidróxidos de ferro invadindo cristal de quarto parcialmente corroído envolto por plasma goethítico da crosta. Aresta horizontal igual a 5,3 mm.

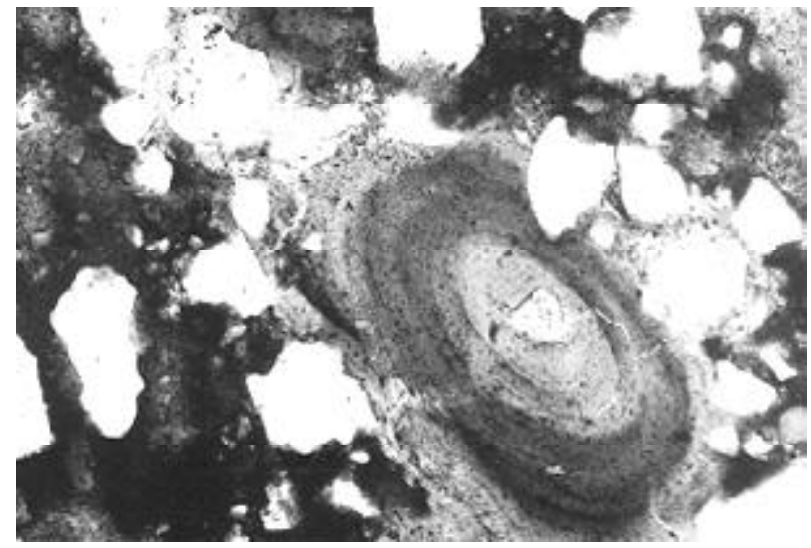

Figura 8: Fotomicrografia em luz natural. Cavidade prenchida por material argilo-ferruginoso, formando estrutura concêntrica (ferriargilan zonado). Aresta horizontal igual a $1,39 \mathrm{~mm}$.

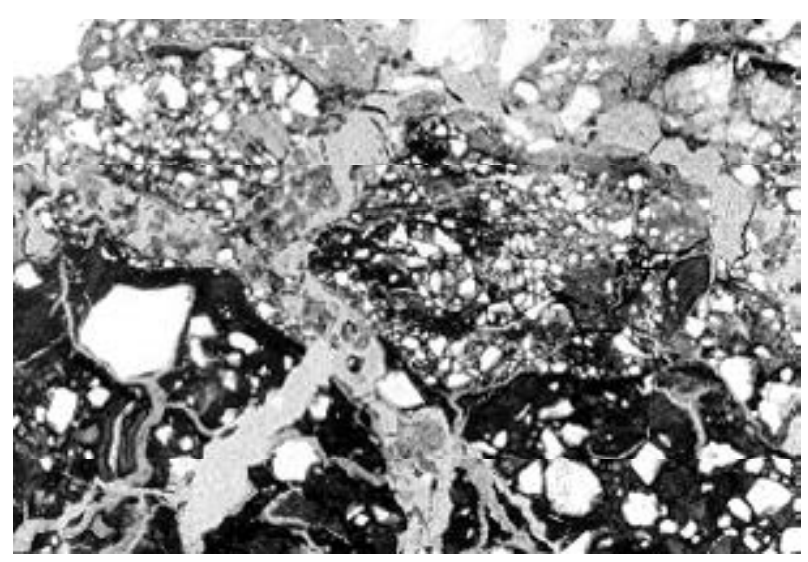

Figura 7 : Fotomicrografia em luz natural, exibindo fissura parcialmente preenchida por plasma caolinítico (porção superior da foto). Na porção inferior, plasma goethítico. Aresta horizontal igual a 5,3 mm. 


\section{Composição química dos materiais}

Dos resultados das análises químicas totais de elementos maiores ( $\mathrm{Si}, \mathrm{Al}$ e Fe, Tabela 1) nos perfis de amostragem observa-se maior concentração de ferro nas crostas (amostras VMC) e de sílica na matriz (amostras VMM). Não há variações na porcentagem de alumínio entre os materiais (matriz versus crostas). Este quadro comprova-se nos diagramas destacados por dois agrupamentos distintos: um de amostras da matriz e outro das amostras das crostas (Figuras 9, diagrama $\mathrm{SiO}_{2} \times \mathrm{Al}_{2} \mathrm{O}_{3}$ e, 10 diagrama $\mathrm{SiO}_{2} \times \mathrm{Fe}_{2} \mathrm{O}_{3}$ ). Os elementos $\mathrm{Ca}, \mathrm{K}$, Na e $\mathrm{Mg}$ ocorrem em menores porcentagens nas amostras da matriz. O titânio permanece estável nos perfis, ocorrendo em concentrações equivalentes, tanto nas amostras da matriz como nas amostras das crostas.

\section{Afloramento de Pirapora do Bom J esus}

\section{Caracterização dos diferentes materiais}

As determinações em DRX e análise de minerais pesados de amostras das crostas ferruginosas e da matriz e do sedimento sem "dobras", evidenciam a presença de quartzo (dominante), goethita, caolinita e, secundariamente, biotita, hematita, ilmenita e gibbsita. Rutilo e zircão sãoacessórios.

A análise micromorfológica das amostras possibilitou o reconhecimento de dois plasmas distintos: um avermelhado e argilo-ferruginoso, nas crostas; e outro, amarelado e caolinítico, na matriz (Figura 11). Os grãos

Tabela 1: Resultados das análises químicas totais das amostras coletadas nos perfis do Afloramento da Rua G irassol -Vila Madalena .

\begin{tabular}{|c|c|c|c|c|c|c|c|c|c|c|}
\hline AMOSTRA & VM1M1 & VM1C/M1 & $\mathrm{VM} 1 \mathrm{C} 2$ & VM2M1 & $\mathrm{VM} 2 \mathrm{C} / \mathrm{M} 2$ & VM2M2 & VM3M1 & VM3C1 & VM3M2 & VM3C3 \\
\hline$\% \mathrm{SiO}_{2}$ & 60,01 & 68,03 & 45,71 & 57,30 & 44,44 & 53,45 & 57,90 & 49,15 & 59,01 & 53,53 \\
\hline$\% \mathrm{Al}_{2} \mathrm{O}_{3}$ & 18,65 & 14,47 & 11,20 & 21,97 & 25,89 & 21,21 & 21,17 & 21,55 & 20,79 & 20,90 \\
\hline$\% \mathrm{Fe}_{2} \mathrm{O}_{3}$ & 10,67 & 7,79 & 32,61 & 8,35 & 13,83 & 12,10 & 8,74 & 15,40 & 8,39 & 11,85 \\
\hline$\% \mathrm{MgO}$ & 0,17 & 0,15 & 0,10 & 0,18 & 0,15 & 0,19 & 0,19 & 0,19 & 0,17 & 0,16 \\
\hline$\% \mathrm{CaO}$ & 0,05 & 0,12 & 0,05 & 0,05 & 0,04 & 0,03 & 0,05 & 0,06 & 0,03 & 0,05 \\
\hline$\% \mathrm{Na}_{2} \mathrm{O}$ & 0,09 & 0,07 & 0,05 & 0,09 & 0,05 & 0,09 & 0,08 & 0,08 & 0,07 & 0,07 \\
\hline$\% \mathrm{~K}_{2} \mathrm{O}$ & 1,38 & 0,99 & 0,67 & 1,35 & 0,80 & 1,68 & 1,49 & 1,51 & 1,40 & 1,20 \\
\hline$\% \mathrm{P}_{2} \mathrm{O}_{5}$ & 0,02 & 0,02 & 0,02 & 0,05 & 0,04 & 0,03 & 0,03 & 0,03 & 0,03 & 0,04 \\
\hline$\% \mathrm{MnO}$ & 0,01 & 0,01 & 0,01 & 0,02 & 0,01 & 0,02 & 0,02 & 0,02 & 0,02 & 0,02 \\
\hline$\% \mathrm{TiO}_{2}$ & 0,98 & 0,83 & 0,69 & 1,42 & 1,28 & 1,19 & 1,09 & 1,19 & 1,57 & 1,48 \\
\hline$\%$ P.F. & 7,79 & 7,33 & 8,78 & 9,24 & 12,81 & 9,05 & 8,96 & 9,75 & 8,36 & 9,34 \\
\hline$\%$ Total & 99,82 & 99,80 & 99,88 & 100,02 & 99,33 & 99,05 & 99,72 & 98,93 & 99,86 & 98,66 \\
\hline$\% \mathrm{H}_{2} \mathrm{O}^{-}$ & 0,92 & 1,01 & 0,95 & 1,63 & 7,41 & 1,43 & 1,23 & 1,08 & 1,33 & 1,02 \\
\hline $\mathrm{Ba}(\mathrm{ppm})$ & 320 & 235 & 165 & 319 & 197 & 390 & 331 & 337 & 325 & 279 \\
\hline $\mathrm{Cr}$ (ppm) & 57 & $<15$ & $<15$ & 114 & 100 & 83 & 69 & 67 & 61 & 71 \\
\hline $\mathrm{Ni}(\mathrm{ppm})$ & $<15$ & $<15$ & $<15$ & $<15$ & $<15$ & $<15$ & $<15$ & 17 & 18 & 22 \\
\hline $\mathrm{Sr}$ (ppm) & 47 & 37 & 30 & 66 & 51 & 47 & 48 & 52 & 65 & 61 \\
\hline $\mathrm{V}$ (ppm) & 120 & 69 & 82 & 370 & 221 & 178 & 122 & 140 & 100 & 161 \\
\hline $\mathrm{Zr}(\mathrm{ppm})$ & 440 & 576 & 423 & 581 & 433 & 396 & 453 & 439 & 574 & 539 \\
\hline
\end{tabular}

As análises em MEV/EDS de amostras do afloramento da Rua Girassol evidenciam que elas compõem-se de grãos de quartzo de tamanho variado, cimentados por material ferruginoso. A matriz intercalada a estas crostas é composta essencialmente por grãos de quartzo equigranulares, poucos cristais placóides de biotita, exibindo baixa concentração de ferro e alumínio no plasma. As análises químicas qualitativas confirmaram os resultados das análises químicas totais, mostrando que as mais altas concentrações de ferro são encontradas nas crostas. de quartzo apresentam-se semi-angulosos, frequientemente corroídos e microfissurados. São comuns litorelíquias constituídas por fragmentos de filito e quartzito. Hidróxidos de ferro são observados nos materiais analisados na forma de fissuras preenchidas por plasma goethítico e caolinítico de diferentes gerações (Figura 12) associados às feições de preenchimento de cavidades por material argilo-ferruginoso (ferriargilans). 


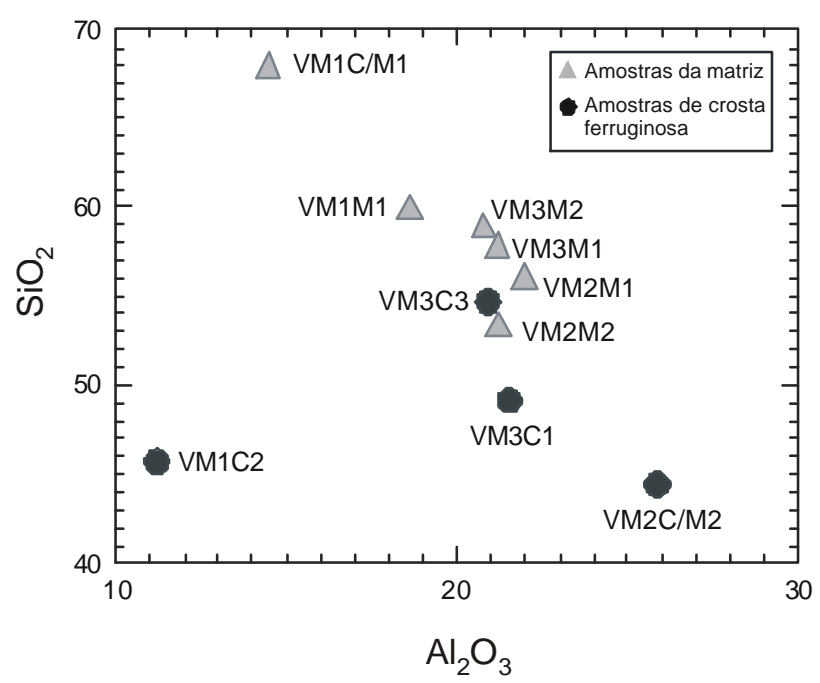

Figura 9: Diagrama $\mathrm{Fe}_{2} \mathrm{O}_{3} \times \mathrm{SiO}_{2}(\%)$, exibindo a distribuição dos campos de agrupamento das amostras (crostas e matriz), em função do comportamento geoquímico dos elementos (Vila Madalena).

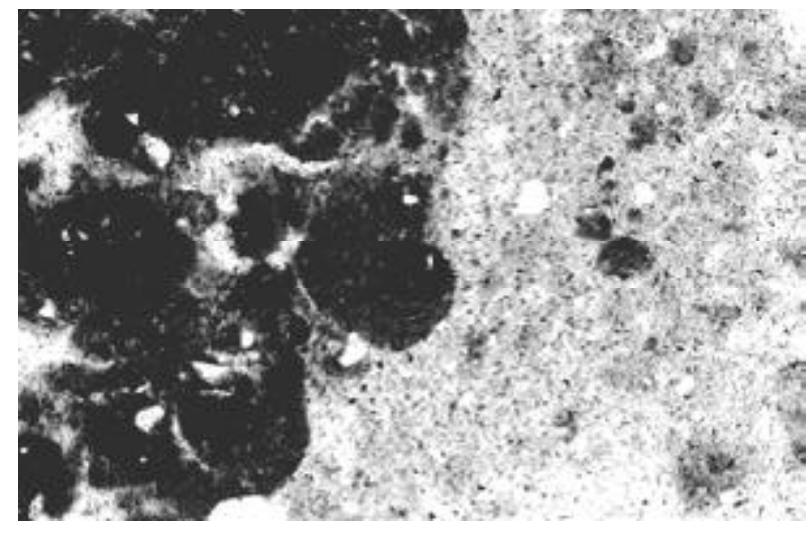

Figura 11: Fotomicrografia em luz natural. Contato entre plasma da crosta (porção mais escura na parte esquerda da foto) e plasma da matriz (porção mais clara, parte direita da foto). Aresta horizontal igual a 5,3 mm.

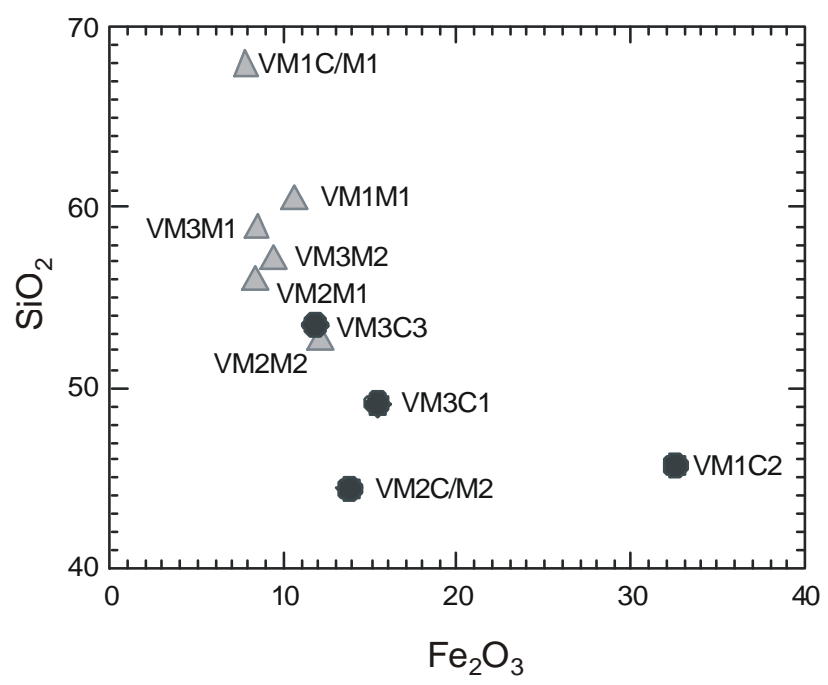

Figura 10: Diagrama $\mathrm{Fe}_{2} \mathrm{O}_{3} \times \mathrm{Al}_{2} \mathrm{O}_{3}(\%)$, exibindo a distribuição dos campos de agrupamento das amostras (crostas e matriz), em função do comportamento geoquímico dos elementos. (Vila Madalena).

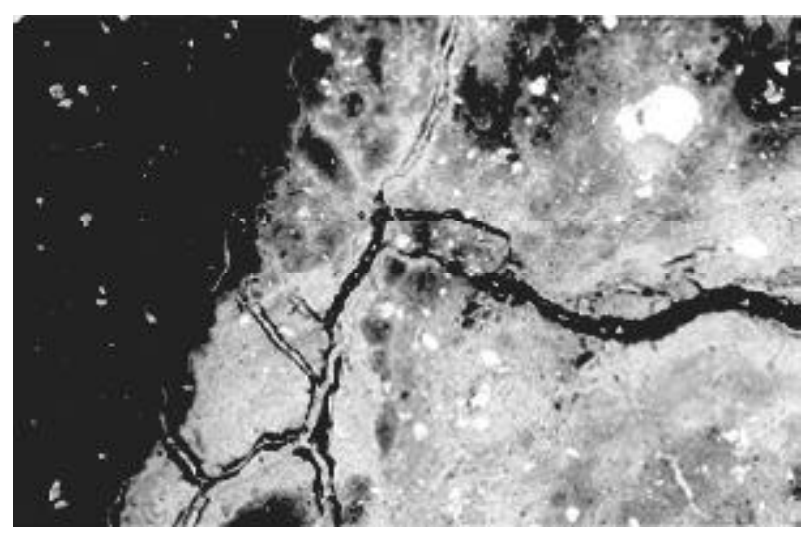

Figura 12: Fotomicrografia em luz natural. Contato entre plasma da crosta goethítica (porção mais escura) e plasma caolinítico da matriz (porção mais clara). Em associação, diferentes fissuras parcialmente preenchidas por goethita. Aresta horizontal igual a 5,3 $\mathrm{mm}$. 


\section{Composição química dos materiais}

Os diagramas geoquímicos construídos a partir dos dados da Tabela 2 exibem a formação de três conjuntos distintos: crostas, matriz e rocha sem deformação. Observa-se que a matriz, quando comparada com as crostas, é empobrecida em $\mathrm{Fe}_{2} \mathrm{O}_{3}$ e enriquecida em $\mathrm{SiO}_{2}$. O sedimento da porção sem "dobras" exibe composição intermediária. $\mathrm{O} \mathrm{Al}_{2} \mathrm{O}_{3}$ exibe concentrações constantes nas amostras analisadas (Figuras 13 e 14, Tabela 2).

Verifica-se na Figura 13 que $\mathrm{Mg}, \mathrm{Ca}$, Na, e K estão sendo eliminados nas amostras das crostas e exibem relativa concentração na matriz e na rocha sem crostas ferruginosas "dobradas" (Figuras 15, 16, 17, 18 e 19). Os resultados das análises químicas pontuais em MEV/EDS confirmaram que o plasma da matriz é mais enriquecido em silício e alumínio. No plasma da região das crostas predomina o ferro. Microfissuras preenchidas por material com alto teor de ferro indicam remobilização de óxidos e hidróxidos de ferro principalmente na interface crosta e matriz. Análise pontual qualitativa em sequiência, nas regiões que compreendem a matriz e crosta, demonstrou nitidamente o aumento nas concentrações de ferro e alumínio, a medida que se avança para a região do plasma correspondente a crosta (Figuras 15, 16, 17, 18 e 19). A sílica, por sua vez, permanece em concentrações constantes ao longo da seção analisada, exceto na re- gião de interface crosta/matriz, quando ocorre aumento significativo no teor de silício.

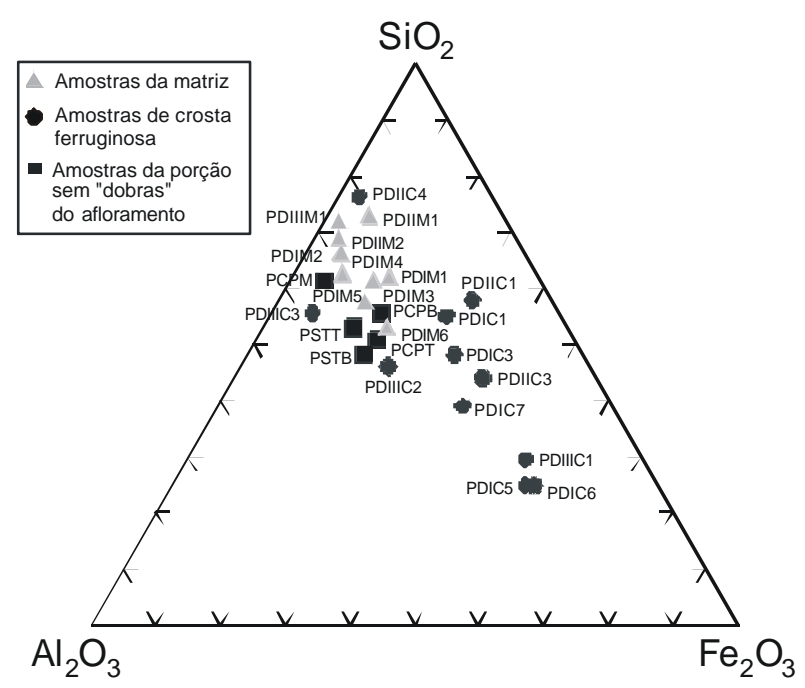

Figura 13: Diagrama triangular $\mathrm{Fe}_{2} \mathrm{O}_{3} \times \mathrm{Al}_{2} \mathrm{O}_{3} \times \mathrm{SiO}_{2}$ (\%), exibindo a distribuição dos conjuntos de amostras. Notase concentrações mais elevadas de Fe nas amostras das crostas e de Si e Al da matriz e da porção sem "dobras" do afloramento de Pirapora.

Ta bela 2: Resultados das análises químicas totais para as amostras coletadas nos perfis do Afloramento de Pirapora do Bom J esus.

\begin{tabular}{|c|c|c|c|c|c|c|c|c|c|c|c|c|c|c|c|c|}
\hline AMOSTRA & $\% \mathrm{SiO}_{2}$ & $\% \mathrm{Al}_{2} \mathrm{O}_{3}$ & $\% \mathrm{Fe}_{2} \mathrm{O}_{3}$ & $\% \mathrm{MgO}$ & $\% \mathrm{CaO}$ & $\% \mathrm{Na}_{2} \mathrm{O}$ & $\% \mathrm{~K}_{2} \mathrm{O}$ & $\% \mathrm{P}_{2} \mathrm{O}_{5}$ & $\% \mathrm{MnO}$ & $\% \mathrm{TiO}_{2}$ & \%P.F. & \%Total & $\% \mathrm{H}_{2} \mathrm{O}^{-}$ & $\mathrm{Ba}(\mathrm{ppm})$ & $\mathrm{Cr}(\mathrm{ppm})$ & $\mathrm{Ni}(\mathrm{ppm})$ \\
\hline \begin{tabular}{|l|} 
PSTT \\
\end{tabular} & 46,23 & 26,35 & 12,25 & 0,38 & 0,04 & 0,13 & 1,42 & 0,03 & 0,02 & 1,71 & 10,92 & 99,47 & 2,38 & 317 & 133 & 51 \\
\hline \begin{tabular}{|l|} 
PSTB \\
\end{tabular} & 42,65 & 27,19 & 16,34 & 0,24 & 0,03 & 0,17 & 1,41 & 0,04 & 0,03 & 1,75 & 10,51 & 100,36 & 1,85 & 306 & 184 & 54 \\
\hline \begin{tabular}{|l|} 
PCPT \\
\end{tabular} & 43,64 & 25,96 & 16,00 & 0,21 & 0,02 & 0,19 & 1,37 & 0,04 & 0,04 & 1,66 & 10,16 & 99,30 & 1,94 & 278 & 208 & 72 \\
\hline \begin{tabular}{|l|} 
PCPB \\
\end{tabular} & 47,94 & 23,81 & 14,69 & 0,20 & 0,02 & 0,19 & 1,35 & 0,03 & 0,03 & 1,64 & 9,31 & 99,22 & 1,89 & 277 & 223 & 77 \\
\hline PCPM & 52,26 & 28,34 & 4,57 & 0,25 & 0,02 & 0,16 & 1,39 & 0,02 & 0,01 & 1,55 & 10,51 & 99,07 & 2,03 & 287 & 121 & 87 \\
\hline PD1M1 & 53,62 & 21,06 & 12,14 & 0,19 & 0,04 & 0,14 & 1,12 & 0,05 & 0,01 & 1,45 & 9,23 & 99,05 & 1,39 & 239 & 176 & 40 \\
\hline PD1C1 & $\begin{array}{l}46,87 \\
\end{array}$ & 18,72 & $\frac{21,94}{21,94}$ & 0,17 & $\begin{array}{l}, 0,03 \\
\end{array}$ & 0,18 & $\begin{array}{l}1,02 \\
1,02\end{array}$ & 0,08 & 0,01 & 1,30 & $\begin{array}{l}0,55 \\
8,55\end{array}$ & $\begin{array}{l}0,80 \\
98,89\end{array}$ & $\frac{1,03}{1,58}$ & 212 & 126 & 33 \\
\hline $\begin{array}{l}\text { PD1M2 } \\
\end{array}$ & 57,36 & 24,37 & 4,64 & 0,21 & 0,02 & 0,15 & 1,29 & 0,03 & 0,01 & 1,61 & 9,11 & 98,82 & 1,99 & 276 & 144 & 43 \\
\hline \begin{tabular}{|l|} 
PD1C3 \\
\end{tabular} & 41,58 & 17,40 & 27,75 & 0,15 & 0,02 & 0,12 & 0,94 & 0,12 & 0,01 & 1,17 & 9,20 & 98,47 & 1,73 & 199 & 290 & 33 \\
\hline \begin{tabular}{|l|} 
PD1M3 \\
\end{tabular} & 53,68 & 22,72 & 11,23 & 0,20 & 0,02 & 0,14 & 1,19 & 0,03 & 0,01 & 1,51 & 9,24 & 99,97 & 2,10 & 254 & 147 & 40 \\
\hline \begin{tabular}{|l|} 
PD1M4 \\
\end{tabular} & 54,08 & 25,85 & 6,66 & 0,21 & 0,02 & 0,16 & 1,28 & 0,04 & 0,01 & 1,62 & 10,07 & 99,99 & 2,02 & 276 & 189 & 49 \\
\hline \begin{tabular}{|l|} 
PD1C5 \\
\end{tabular} & 21,69 & 17,80 & 47,69 & 0,09 & 0,06 & 0,04 & 0,40 & 0,06 & 0,01 & 0,85 & 9,61 & 98,31 & 1,69 & 105 & 184 & 32 \\
\hline \begin{tabular}{|l} 
PD1M5 \\
\end{tabular} & 49,58 & 24,69 & 11,44 & 0,20 & 0,03 & 0,16 & 1,25 & 0,03 & 0,01 & 1,63 & 9,89 & 98,91 & 1,71 & 264 & 162 & 29 \\
\hline PD1C6 & 21,47 & 16,89 & 48,01 & 0,08 & 0,03 & 0,03 & 0,46 & 0,04 & 0,02 & 0,98 & 10,17 & 98,18 & 1,66 & 126 & 48 & 25 \\
\hline \begin{tabular}{|l} 
PD1M6 \\
\end{tabular} & 45,86 & 24,07 & 16,59 & 0,19 & 0,06 & 0,16 & 1,17 & 0,04 & 0,01 & 1,57 & 10,37 & 100,08 & 1,76 & 239 & 202 & 32 \\
\hline \begin{tabular}{|l|} 
PD1C7 \\
\end{tabular} & 34,09 & 20,39 & 33,35 & 0,15 & 0,03 & 0,13 & 0,98 & 0,03 & 0,02 & 1,35 & 10,08 & 100,60 & 1,43 & 205 & 154 & 46 \\
\hline \begin{tabular}{|l} 
PDIIM1 \\
\end{tabular} & 65,66 & 18,64 & 5,73 & 0,08 & 0,01 & 0,03 & 0,38 & 0,03 & 0,02 & 1,02 & 8,97 & 100,57 & 1,80 & 98 & 39 & 18 \\
\hline \begin{tabular}{|l} 
PDIIC1 \\
\end{tabular} & 52,57 & 10,95 & 27,36 & 0,04 & 0,01 & 0,03 & 0,24 & 0,03 & 0,01 & 0,62 & 9,01 & 100,86 & 1,91 & 51 & 90 & $<15$ \\
\hline \begin{tabular}{|l} 
PDIIIM2 \\
\end{tabular} & 60,52 & 23,88 & 3,36 & 0,11 & 0,01 & 0,04 & 0,60 & 0,04 & 0,01 & 1,15 & 9,93 & 99,65 & 1,71 & 164 & 58 & 21 \\
\hline PDIIC3 & 39,14 & 15,64 & 34,26 & 0,07 & 0,02 & 0,03 & 0,42 & 0,04 & 0,01 & 0,86 & 9,28 & 99,77 & 1,61 & 107 & 87 & 25 \\
\hline \begin{tabular}{|l|} 
PDIIC4 \\
\end{tabular} & 68,26 & 18,36 & 2,72 & 0,08 & 0,01 & $0,0,03$ & $\begin{array}{l}, 37 \\
0,38\end{array}$ & 0,04 & 0,02 & 0,96 & $\begin{array}{l}0,66 \\
9,66\end{array}$ & 100,52 & 2,08 & 101 & 43 & 18 \\
\hline PDIIIM1 & 62,29 & 23,80 & 2,33 & 0,19 & 0,03 & 0,18 & 1,34 & 0.02 & 0,01 & 1,60 & 8,09 & $\begin{array}{l}99,89 \\
\end{array}$ & 2,00 & 280 & 169 & 51 \\
\hline \begin{tabular}{|l} 
PDIIIC1 \\
\end{tabular} & 25,66 & 15,56 & 45,22 & 0,09 & 0,03 & 0,04 & 0,24 & 0,06 & 0,01 & 0,78 & 11,70 & 99,40 & 1,71 & 105 & 99 & 36 \\
\hline PDIIIC2 & 40,67 & 26,01 & 19,24 & 0,15 & 0,03 & 0,05 & 0,76 & 0,11 & 0,01 & 1,37 & 11,50 & 99,90 & 1,77 & 181 & 140 & 33 \\
\hline \begin{tabular}{|l|l|l|} 
PDIIC3 \\
\end{tabular} & 46,51 & 31,93 & 5,33 & 0,17 & 0,01 & 0,05 & 0,93 & 0,06 & 0,01 & 1,82 & 12,68 & 99,50 & 2,18 & 231 & 83 & 38 \\
\hline \begin{tabular}{|l|} 
DTICF \\
\end{tabular} & 21,63 & 17,61 & 48,39 & 0,09 & 0,06 & 0,05 & 0,40 & 0,08 & 0,01 & 0,85 & 11,83 & 100,99 & 2,02 & 102 & 180 & 18 \\
\hline \begin{tabular}{|l|} 
DTICS \\
\end{tabular} & 21,62 & 16,76 & 50,17 & 0,09 & 0,03 & 0,04 & 0,41 & 0,05 & 0,02 & 1,00 & 10,95 & 101,12 & 2,85 & 130 & 34 & 36 \\
\hline \begin{tabular}{|l} 
DTIIM1 \\
\end{tabular} & 69,71 & 18,49 & 2,56 & 0,07 & 0,01 & 0,03 & 0,37 & 0,03 & 0,02 & 0,95 & 7,64 & 99,89 & 1,83 & 103 & 17 & $<15$ \\
\hline \begin{tabular}{|l|} 
DTIIC1 \\
\end{tabular} & 53,90 & 10,93 & 28,82 & 0,03 & 0,02 & 0,03 & $\begin{array}{l}0,22 \\
\end{array}$ & 0,03 & 0,01 & 0,62 & 6,80 & 101,42 & 0,99 & 54 & 85 & $<15$ \\
\hline \begin{tabular}{|l} 
DTIIM2 \\
\end{tabular} & 65,67 & 18,61 & 5,60 & 0,07 & 0,01 & 0,04 & 0,37 & 0,03 & 0,02 & 1,00 & 7,74 & 99,17 & 1,28 & 100 & 15 & $<15$ \\
\hline \begin{tabular}{|l|l|l|} 
DTI \\
\end{tabular} & 39,54 & 15,50 & 35,08 & 0,08 & 0,02 & 0,03 & 0,42 & 0,05 & 0,01 & 0,89 & 9,31 & 100,93 & 2,59 & 110 & 74 & $<15$ \\
\hline \begin{tabular}{|l|} 
DTIIIM3 \\
\end{tabular} & $\begin{array}{l}0,04 \\
60,43\end{array}$ & 23,55 & 3,19 & 0,11 & $\begin{array}{l}, 0,02 \\
0,\end{array}$ & 0,05 & $\begin{array}{l}0,56 \\
0,56\end{array}$ & 0,06 & 0,01 & 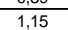 & $\begin{array}{l}, 0,49 \\
9\end{array}$ & 98,62 & $\begin{array}{l}1,99 \\
1,99\end{array}$ & 162 & 37 & $<15$ \\
\hline \begin{tabular}{|l|} 
DTIIIIC1 \\
\end{tabular} & 25,44 & 15,28 & 45,81 & 0,08 & 0,04 & 0,07 & 0,44 & 0,07 & 0,01 & 0,78 & $\frac{2,79}{11,91}$ & 99,93 & 2,46 & 107 & 90 & 31 \\
\hline \begin{tabular}{|l|} 
DTIIIM1 \\
\end{tabular} & 39,63 & 25,79 & 19,32 & 0,14 & 0,02 & 0,05 & 0,70 & 0,12 & 0,01 & 1,36 & 12,26 & 99,40 & 2,23 & 176 & 124 & 21 \\
\hline \begin{tabular}{|l|} 
DTIIIIC/M1 \\
\end{tabular} & 46,22 & 31,89 & 5,15 & 0,17 & 0,02 & 0,06 & 0,90 & 0,08 & 0,01 & 1,81 & 12,57 & 98,88 & 2,06 & 235 & 61 & $<15$ \\
\hline \begin{tabular}{|l|}
$\mathrm{DT}$ TIIIC/M2 \\
\end{tabular} & 30,99 & 22,25 & 33,73 & 0,12 & 0,03 & 0,06 & 0,62 & 0,07 & 0,01 & 1,19 & 12,23 & 101,29 & 1,98 & 155 & 74 & $<15$ \\
\hline
\end{tabular}




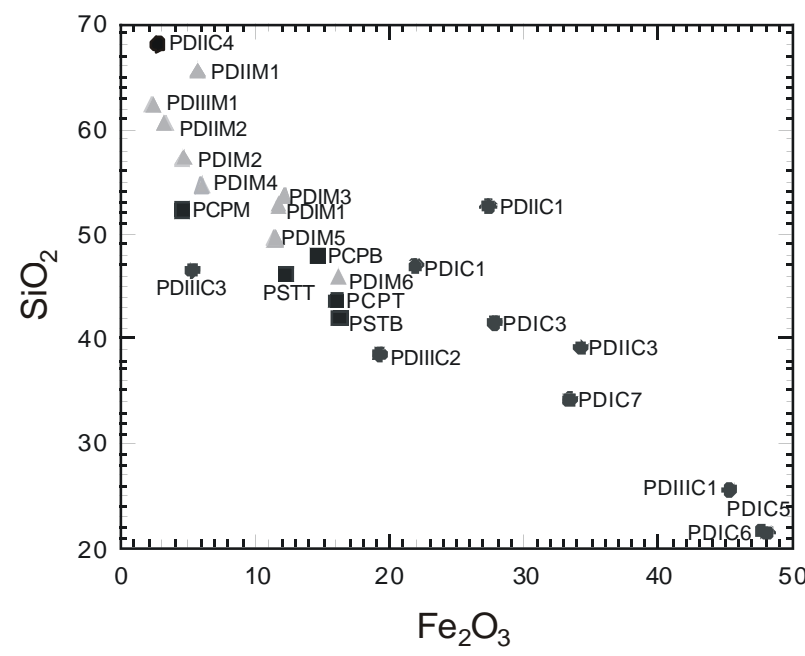

Figura 14: Diagrama $\mathrm{Fe}_{2} \mathrm{O}_{3} \times \mathrm{SiO}_{2}$ (\%), exibindo a distribuição dos campos de agrupamento das amostras em função do conteúdo químico dos elementos. O bservase concentração mais elevada de Fe nas amostras das crostas e de Si, na matriz. As amostras da porção sem "dobras" localizam-se no campo intermediário do diagrama (Pirapora).

3. [:WE I

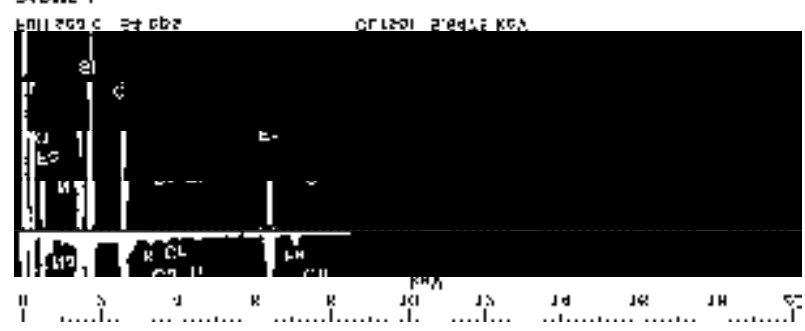

Figura 16: Espectro EDS de análise qualitativa do ponto 1 assinalado na Figura 15. Determinação na região compreendida por crosta. Picos de ferro, oxigênio e silício destacados, e picos de titânio, potássio, sódio, cálcio e magnésio, menos expressivos.

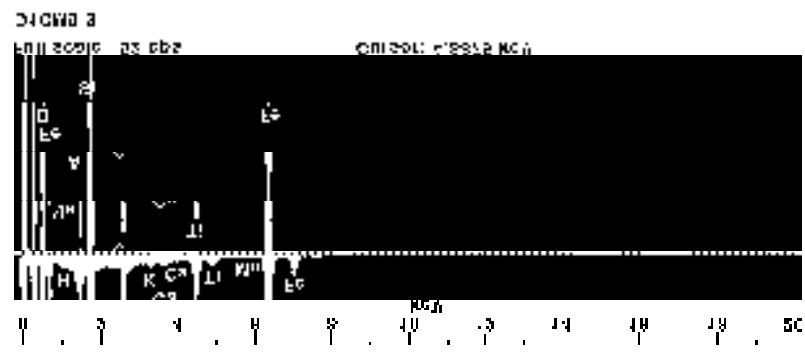

Figura 18: Espectro EDS de análise qualitativa do ponto 3 assinalado na Figura 15. Determinação na região compreendida por crosta. Picos de ferro, oxigênio, silício e titânio destacados e picos do potássio, sódio, cálcio e magnésio, manganês e alumínio menos expressivos.

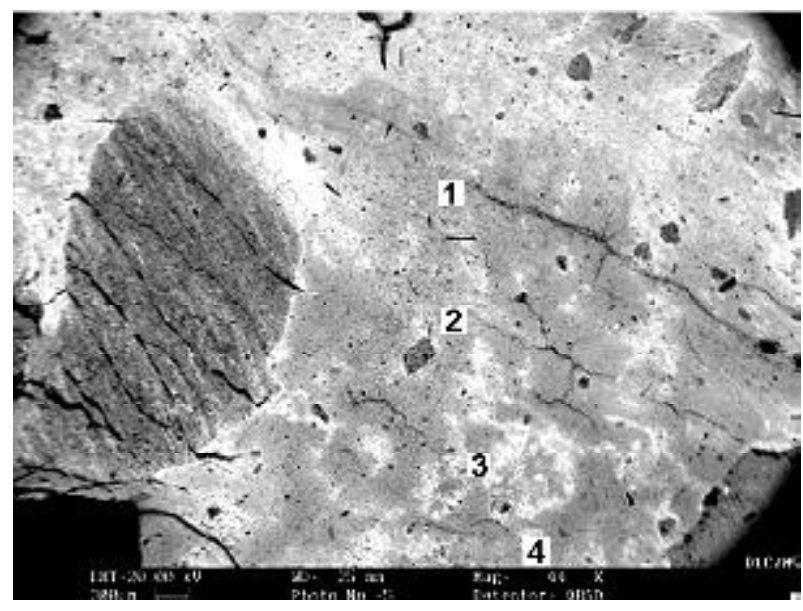

Figura 15: Imagem de MEV. Aspecto geral do plasma das crostas (afloramento de Pirapora) exibindo fissuras preenchidas por hidróxido de ferro, à direita, e litorelíquia, à esquerda. Pontos 1, 2, 3, 4 representam análises pontual qualitativa.

[us entas

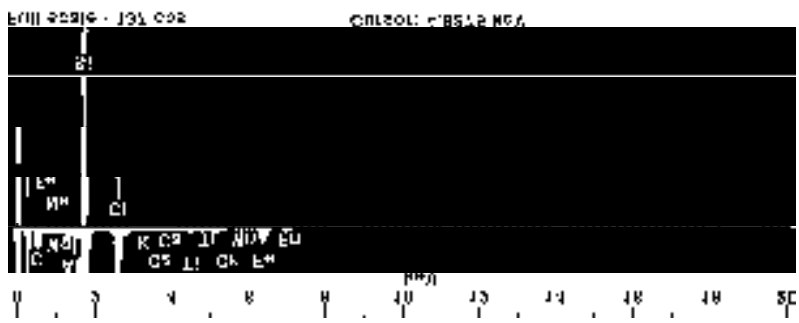

Figura 17: Espectro EDS de análise qualitativa do ponto 2 assinalado na Figura 15. Determinação na região compreendida por crosta. Picos de ferro, oxigênio e silício destacados, e picos do titânio, potássio, sódio, cálcio e magnésio menos expressivos e adição do alumínio.

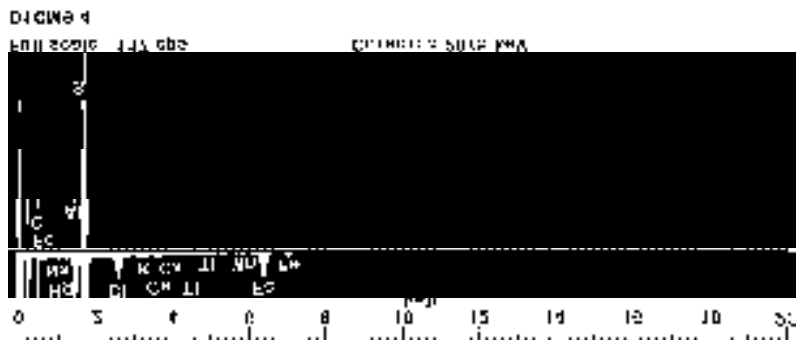

Figura 19: Espectro EDS de análise qualitativa do ponto 4 assinalado na Figura 15. Determinação na região compreendida pela crosta. Picos de ferro, oxigênio, silício menos destacados que a Figura 18, e picos do potássio, sódio, cálcio e magnésio pouco individualizados; os picos de manganês e alumínio são quase inexistentes. 


\section{ANÁLISE ESTRUTURAL}

\section{Afloramento da Vila Madalena}

Nesta área foram obtidas medidas estruturais das crostas deformadas encontradas no lado esquerdo do afloramento (Figura 20). As dobras identificadas caracterizam um antiforme com flanco direito com mergulho alto para SE e flanco esquerdo mergulhando suavemente para NW.

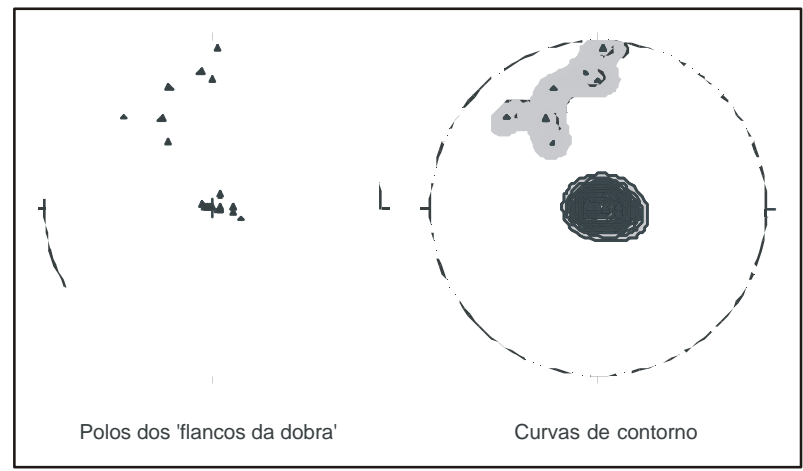

Figura 20: Estereogramas Schimidt Lambert construídos com os dados levantados no afloramento da Vila Madalena.

\section{Afloramento de Pirapora do Bom J esus}

O estereograma construido a partir dos dados de juntas e fraturas recolhidos em campo (Figura 21) apresenta orientação principal NNE-SSW, com mergulhos altos $\left(90^{\circ}\right.$ e $65^{0}$ ) e espaçamentos decimétricos. O resultado do estereograma Schmidt Lambert confeccionado a partir dos dados obtidos em campo (Figura 21) coincide com o estereograma para clivagem de crenulação S3 de Bergmann (1988), baseado em levantamentos estruturais realizados em rochas do grupo São Roque (Figura 22). No entanto, não apresenta coincidência com os resultados de Bistrich (1982), também em rochas do grupo São Roque (Figura 23). Isto talvez se explique pelo fato destes dados serem representativos de feições regionais ou por eles serem oriundos de estruturas relacionadas a eventos distintos.

O estereograma representativo dos pólos da superfície "dobrada" exibe distribuição preferencial E-W (Figuras 24 e 25) e apesar da dispersão exibida no diagrama, defi- ne uma guirlanda com eixo geométrico construído S13W/ $4^{0}$. Tal tipo de dobramento não corresponde a nenhum padrão estrutural apresentado em trabalhos realizados por outros pesquisadores em rochas do Grupo São Roque. Os estereogramas resultantes das projeções dos polos das superfícies "dobradas" também exibem maiores concentrações de pólos no eixo E-W, dispondo-se em círculo mínimo, configurando assim geometria de dobras cônicas (Stauffer, 1964 apud Hobbs et al., 1976).

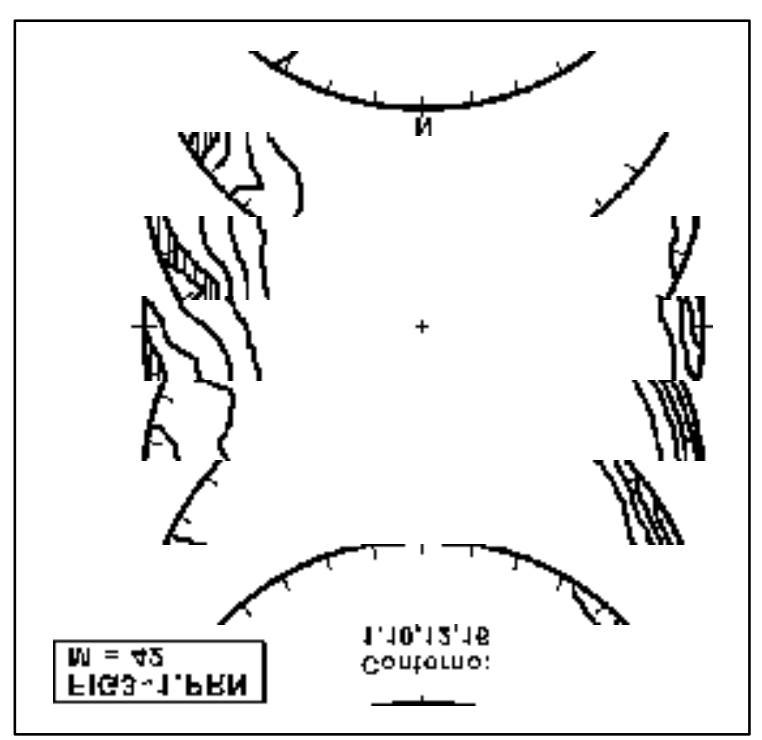

Figura 21 : Estereograma das fraturas do afloramento de Pirapora.

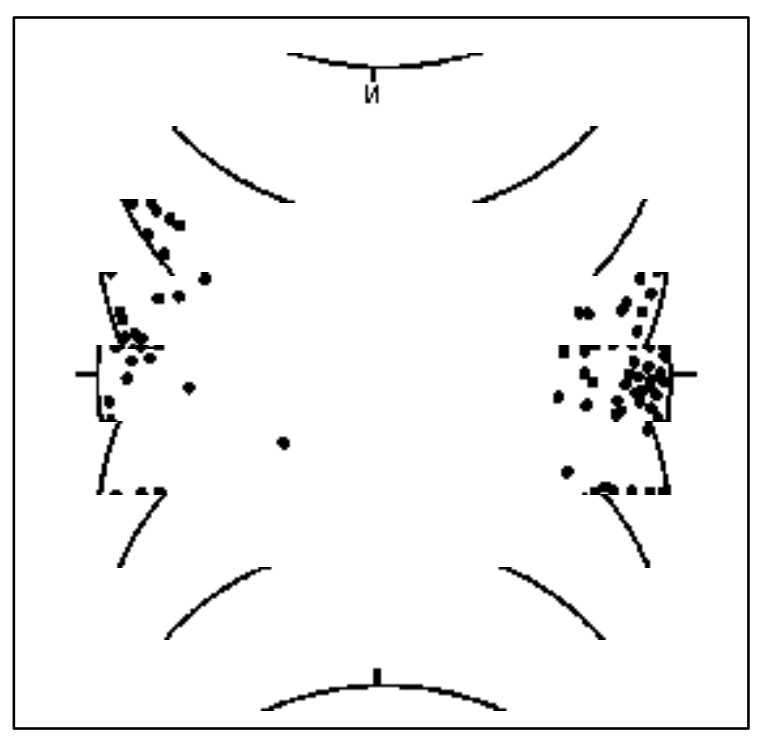

Figura 22: Estereograma da clivagem S3 de crenulação de Bergmann (1988). 


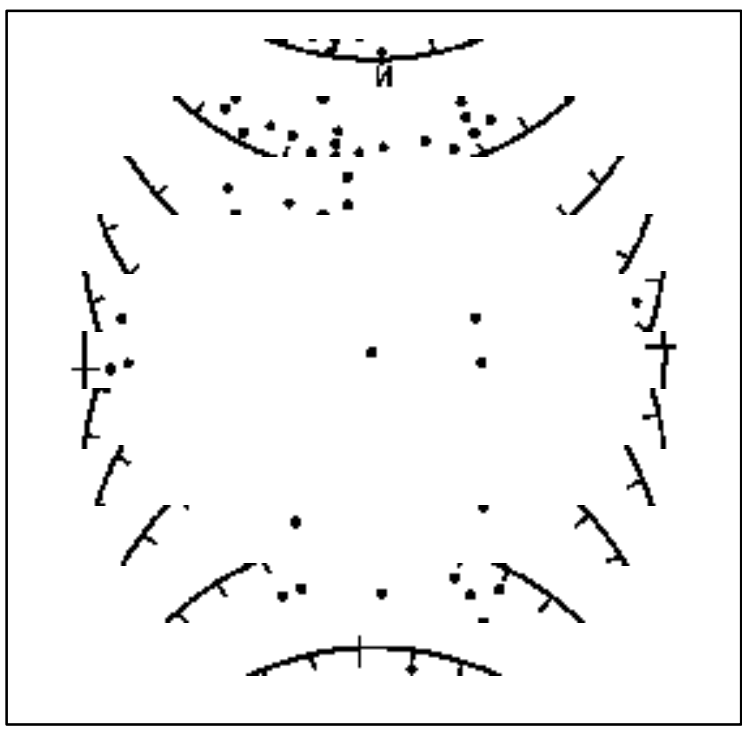

Figura 23: Estereograma da clivagem de crenulação de Bistrich (1982).

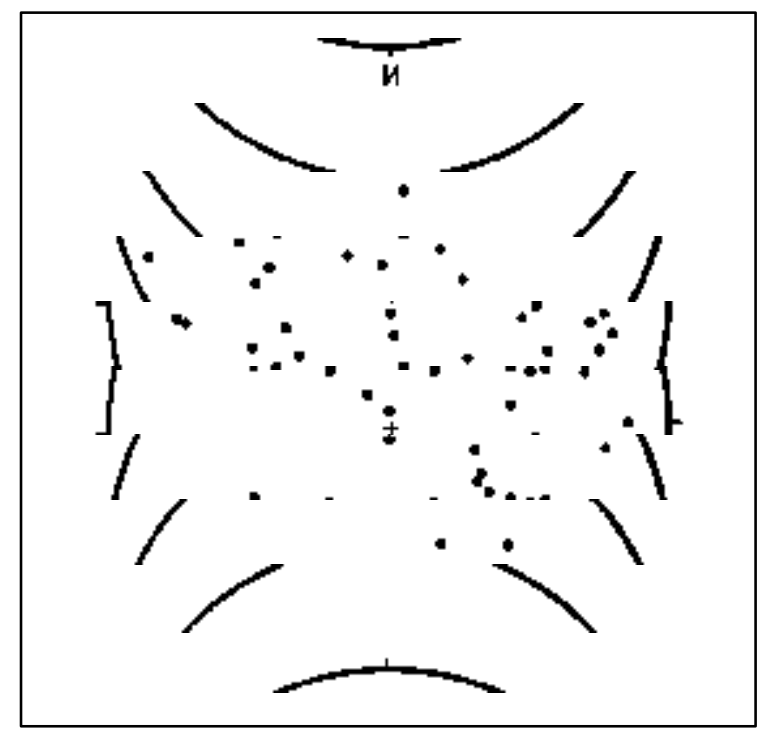

Figura 24: Estereograma de Schimidt-Lambert para os pólos dos flancos de dobras do afloramento.

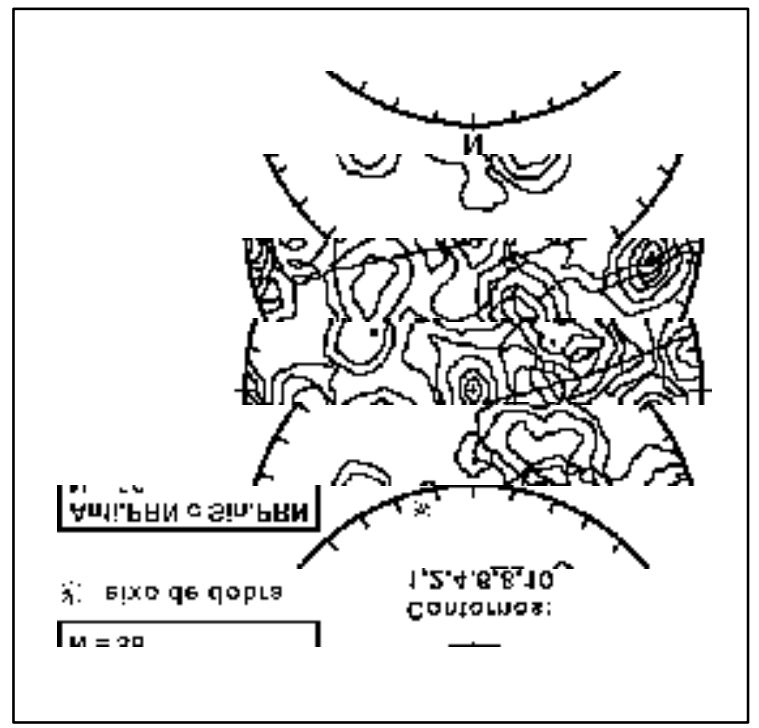

Figura 25: Curvas de contorno e guirlanda com Eixo construído para os dados da Figura 24.

\section{DISCUSSÃO}

Simplificadamente, a composição mineral das crostas ferruginosas e dos sedimentos encaixantes são semelhantes. As diferenças observadas ficam por conta de grãos de quartzo parcialmente corroídos com evidência de dissolução. Esta feição de corrosão provém da dissolução da sílica promovida pela degradação química dos materiais, responsável também pela concentração de hidróxidos de ferro (ferralitização).

Em seção delgada, grãos, nódulos e litorelíquias estão cimentados por goethita nas crostas ferruginosas e por caolinita nos sedimentos encaixantes. Reconhece-se como volumes principais os produtos secundários formados pela remobilização e concentração de hidróxidos de ferro. Como volumes secundários, hidróxidos de alumínio e argilas, ocorrem como recobrimentos, nódulos e preenchimento de poros e de fissuras.

Os diagramas geoquímicos sugerem origem comum para as crostas ferruginosas a partir dos sedimentos encaixantes. A diferença exibida reflete-se apenas no empobrecimento de $\mathrm{Fe}_{2} \mathrm{O}_{3}$ e enriquecimento de $\mathrm{SiO}_{2}, \mathrm{Al}_{2} \mathrm{O}_{3} \mathrm{e}$ elementos alcalinos na matriz, inverso do que foi notado nas crostas. Tal aspecto sugere origem para as crostas a partir da cimentação de óxidos e hidróxidos de ferro remobilizados da própria rocha encaixante durante deslo- 
camento descendente do nível hidrostático, razão pela qual a matriz é menos ferruginosa e guarda componentes originais da rocha como elementos alcalinos e alumínio, enquanto as crostas são horizontes intensamente ferruginizados (30 a $50 \%$ de $\mathrm{Fe}_{2} \mathrm{O}_{3}$ ), na forma de óxidos, hidróxidos e sílica (20 a $50 \%$ ).

Havendo crostas ferruginosas, o sedimento encaixante está deferruginizado. Esta feição é observada em campo e comprovada com base nos resultados analíticos obtidos nos materiais coletados nas duas áreas.

As crostas arqueadas, observadas no afloramento da Vila Madalena, originaram-se a partir da migração de hidróxidos de ferro a partir da deposição de sucessivas "frentes de precipitação" destes hidróxidos. Dentre as condições químicas que permitem a solubilidade de ferro incluem a permanência no estágio de valência $2^{+}$. Esta condição somente é obtida em ambiente redutor sob condições de $\mathrm{pH}$ ácido. Como está evidenciada a mobilidade do ferro nas áreas estudadas, conclui-se que em determinado momento estas áreas encontraram-se sob estas condições. Fator que pode ter corroborado para esta condição pode ter sido a elevada precipitação pluviométrica, juntamente com a remobilização de ácidos húmicos provenientes da decomposição de matéria orgânica do horizonte superficial do solo. A migração de fluxos d'água descendentes em direção ao nível hidrostático $(\mathrm{NH})$, conduziram ferro e outros elementos solubilizados para porções inferiores do perfil de alteração. Sob condições favoráveis de precipitação, "frentes de oxidação" formaram-se dando origem à zonas de deposição de hidróxidos de ferro. Este processo repete-se a cada novo período de precipitação pluviométrica mais intensa de formação das crostas dobradas. Suguio \& Barbour (1969) consideram que as deposições de hidróxidos de ferro possuem forma de arcos ou leques a partir de frentes de deposição. Estas ao encontrarem obstáculos representados pela diferença de permeabilidade dos sedimentos ou pela interceptação de outras "frentes" adjacentes acabam "deformando-as".

Em Pirapora do bom Jesus, a linha de fragmentos de couraça (stone line) observada na porção NE do afloramento (Figura 1), formada pela degradação e desmantelamento físico da couraça ferruginosa superior, representa evidência clara de campo de que houve soerguimento do relevo local.

Em conexão com esta evidência, supõe-se que eventos tectônicos recentes reativaram os sistemas de falhas regionais (Taxaquara, Jundiuvira e Romeiros) produzindo os sistemas de fraturas (G1, G2, G3 e G4), observadas em Pirapora (Figura 26 - Estágio 1). As fraturas dos grupos G1, G2 e G3 teriam direcionado o fluxo d'água para o interior das mesmas, visto que a rocha mãe é pouco per- meável e a existência de fraturas proporciona maior permeabilidade, permintindo assim maior percolação de água e passagem de materiais lixiviados pelas mesmas.

Diante da ascensão topográfica, o nível hidrostático (NH) passa a ser rebaixado em relação ao relevo. Períodos de maior umidade (chuvoso) conduzem o NH a porções superiores e, nas secas, a porções inferiores. No entanto, o movimento relativo do $\mathrm{NH}$ era sempre descendente. Desta forma, óxidos e hidróxidos de ferro da rocha original foram remobilizados e concentrados em zonas mais profundas do perfil de alteração. Este movimento relativo permitiu que hidróxidos de ferro e, secundariamente, hidróxidos de alumínio e argilas fossem precipitados ao longo das fraturas (F) dos grupos G1 e G2, observadas em Pirapora (Figura 4). Crostas ferruginosas oblíquas às fraturas foram formadas a partir de estrutura tipo "pena" (cone de rebaixamento gerado pela ascensão do relevo (Figura 26 - Estágio inicial). O conjunto formado pela junção dessas estruturas caracteriza a feição de "dobras", que aparece no afloramento de Pirapora (Figura 26 - Estágios 2 e 3). Posteriormente, crostas ferruginosas "dobradas" antigas foram cortadas por falhas (G4) (Figura 4, F7, F10 e F11 e Figura 26 - Estágio 4), provavelmente relacionadas a último evento de reativação do sistema de falhas acima mencionado.

\section{CONCLUSÕES}

As crostas ferruginosas apresentam organização textural, composição química e mineral semelhantes, embora estejam encaixadas em litologias distintas. Isto sugere que as crostas sejam horizontes mais ferruginizados, originados a partir da cimentação por óxidos e hidróxidos de ferro provenientes dos próprios sedimentos encaixantes. Mineralogicamente, as crostas ferruginosas não fogem a regra geral quanto a composição mineral, sendo constituidas por goethita, o hidróxido de ferro mais comum nestes materiais.

Não foi encontrada qualquer relação geométrica entre "dobras" das crostas ferruginosas de Vila Madalena e as dobras regionais. As dobras encontradas nas crostas ferruginosas de Pirapora do Bom Jesus não exibem relações diretas com os padrões tectônicos de dobras descritas regionalmente (Bistrich, 1982; Bergmann, 1988). Vale ressaltar a importância das fraturas instaladas por provável reativação tectônica (Quaternária) de sistemas de falhas regionais, as quais geraram deformação em depósitos sedimentares na porção centro oriental do Estado de São Paulo (Riccomini, 1995). Estas estruturas teriam propiciado o condicionamento do fluxo d'água para seu interior, 


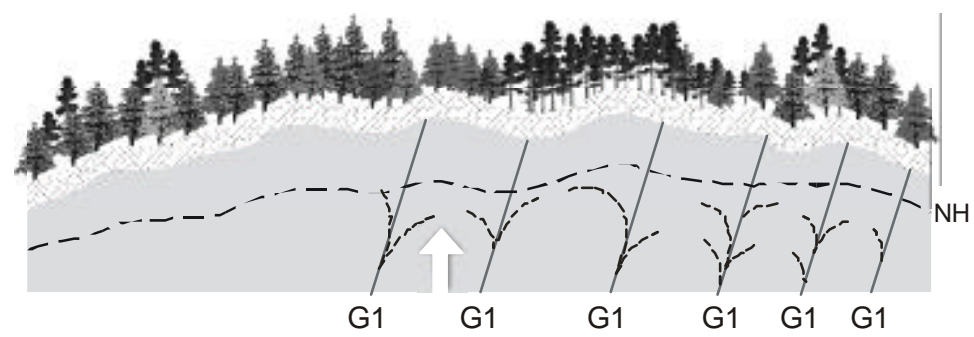

ESTÁGIO INICIAL - Implantação das fraturas do grupo G1, com ascenção do relevo. Primeiro evento neotectônico.

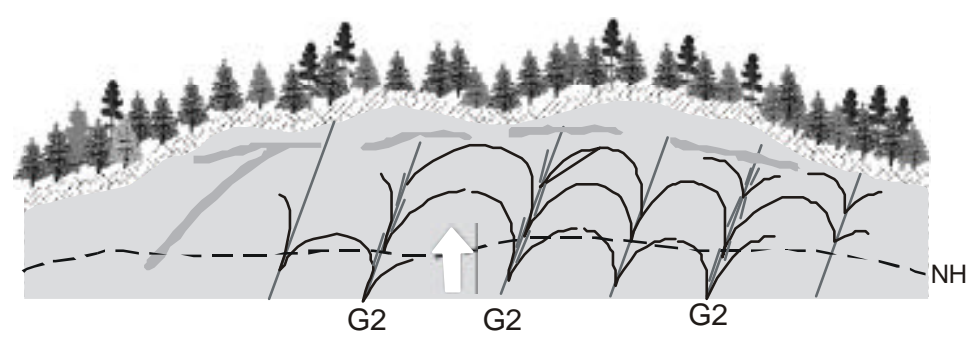

ESTÁGIO 2 - Reativação das fraturas do grupo G1, formando o grupo G2 (fraturas múltiplas). Segundo evento neotectônico. Início de formação das crostas dobradas.

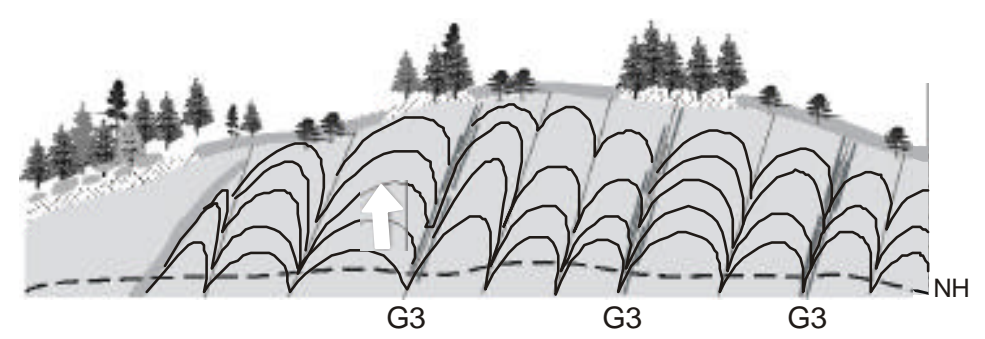

ESTÁGIO 3 - Formação de novas fraturas similares ao grupo G1, gerando o grupo G3 e intensificando as fraturas múltiplas (grupo G3). Terceiro evento neotectônico. Desenvolvimento máximo das crostas de superfície e das crostas dobradas.

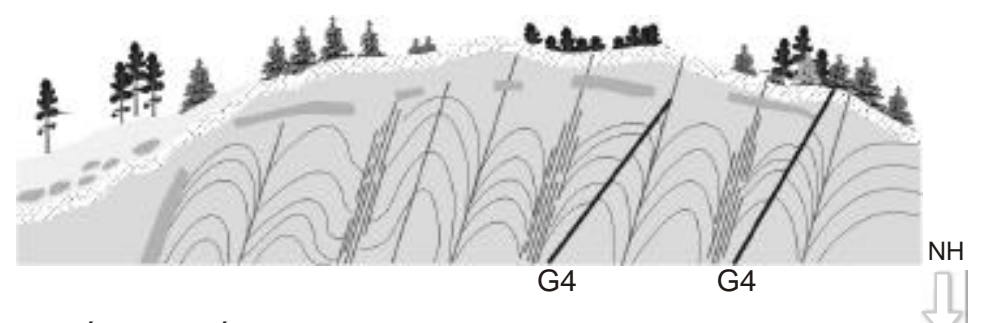

ESTÁGIO 4 - Último evento neotectônico com instalação das falhas do grupo $G 4$

Figura 26: Esquema evolutivo das crostas deformadas de Pirapora do Bom Jesus, baseado na proposta de origem geoquímica para estas estruturas. $\mathrm{NH}$ compreende o posionamento do nível hidrostático no decorrer da evolução das crostas. 
originando as crostas ferruginosas "dobradas".

As crostas ferruginosas são de origem genuinamente geoquímica, formadas por processos de remobilização e concentração de óxidos e hidróxidos de ferro e, secundariamente, de hidróxidos de alumínio e diferentes argilominerais, em resposta ao deslocamento descendente do nível hidrostático $(\mathrm{NH})$.

\section{AGRADECIMENTOS}

Os autores agradecem o apoio recebido pela FAPESP no projeto de Auxílio à Pesquisa n ${ }^{0}$ 97/00764-6.

\section{REFERÊN CIAS BIBLIOGRÁFICAS}

AMBROSI, A. ; NAHON, D. (1986) Petrological and geochemical diferentiation of lateritic iron crust profiles. Chemical Geology, v. 57, p. 371-393.

BEAUVAIS, A. ; COLIN, F. (1993) Formation and transformation process of iron duricrust systems in tropical humid environment. Chemical Geology, v.106, p. 77-101.

BERGMANN, M. (1988) Caracterização estratigráfica e estrutural da seqüência vulcano-sedimentar do Grupo São Roque, na região de Pirapora do Bom
Jesus. São Paulo, 155p. Dissertação (Mestrado) Instituto de Geociências, Universidade de São Paulo.

BISTRICH, C. A. (1982) Geologia do Sinclinório de Pirapora, SP. São Paulo, 92p. Dissertação (Mestrado) - Instituto de Geociências, Universidade de São Paulo.

GOUDIE, A. (1973) Duricrusts in tropical and subtropical landscapes. Oxford, Clarendon. 174p.

HOBBS, B.E. ; MEANS, W.D. ; WILLIANS, P.F. (1976) An outline of structural geology. New York, John Wiley. 571p.

RICCOMINI, C. (1995) Tectonismo gerador e deformador dos depósitos pós-gondwanicos da porção centro oriental do Estado de São Paulo e áreas vizinhas. São Paulo, 100p. Tese (LivreDocência) - Instituto de Geociências, Universidade de São Paulo.

SÍGOLO, J. B. ; OHNUMA, C. S. (1996) Provável modelo de origem e evolução dos horizontes ferruginosos da Bacia de São Paulo com base na geoquímica de superfície. Boletim. Instituto de Geociências. Série Científica, n. 27, p.137-149.

SUGUIO, K.; BARBOUR, A. P. (1969) Morfologia e gênese das estruturas limoníticas dos sedimentos da Bacia de São Paulo. Anais da Academia Brasileira de Ciências, v. 41, n. 2, p.161-180. 